\title{
Perencanaan Septic Tank Skala Rumah Tangga Untuk Penanganan Air Limbah
}

\author{
Rudy Yoga Lesmana \\ Program Studi Teknik Lingkungan Universitas Muhammadiyah Palangkaraya \\ *email: yoga.lesmana@umpalangkaraya.ac.id
}

\begin{abstract}
ABSTRAK. Air limbah yang dihasilkan dari kegiatan rumah tangga jika tidak dikelola dengan baik maka akan menimbulkan masalah yang serius bagi lingkungan. Salah satu solusi dalam mengatasi permasalahan air limbah, yang ada di Indonesia yaitu dengan menggunakan septic tank. Septic tank umum digunakan di Indonesia karena menggunakan prinsip anaerob, yang hanya dibuat kemudian dibiarkan saja, tanpa perawatan yang rutin, dan jika ingin operasionalnya optimal maka perlu dikuras dengan jangka waktu 1 kali dalam setahun. Penelitian ini bertujuan untuk mengetaui Perkiraan kualitas dari effluent (BOD \& COD) septic tank dan Berapa kapasitas volume dari septic tank untuk rumah tempat tinggal. Metode penelitian Besaran air limbah yang dihasilkan dari kegiatan rumah tangga menuju septic tank menurut Jayanudin (2016), adalah sebesar $120 \mathrm{~L} /$ hari atau 0,12 $\mathrm{m}^{3} /$ hari dengan jumlah anggota keluarga ideal yaitu 5 orang. Dalam penelitian ini, air limbah mengalir selama 12 jam yang berasal dari kegiatan rumah tangga. Kadar COD yang dihasilakan Effluent pada septic tank ini adalah sebesar 207 mg/ltr dan COD Removal rate sebesar 31,5\%, sedangkan Kadar BOD yang dihasilkan Effluent pada septic tank ini sebesar $411 \mathrm{mg} / \mathrm{l}$ dan BOD removal rate sebesar 31,5\%. Untuk Akumulasi Volume lumpur yang dihasilkan selama 2 tahun (24 Bulan) adalah sebesar $0,081 \mathrm{~m}^{3}$. Penurunan volume lumpur/sludge pada septic tank sebesar $68 \%$ atau Setelah 24 bulan volume lumpur menjadi $0,055 \mathrm{~m}^{3}$, semakin lama waktu penyimpanan lumpur di septic tank maka volumenya akan semakin berkurang. Volume septic tank yang dibutuhkan untuk menginapkan limbah selama 15 jam adalah sebesar 0,075, Semakin lama waktu Hydraulic retention time (HRT)/waktu tinggal limbah, maka akan semakin baik penguraian mikroorganisme dalam septic tank serta sebaliknya, semakin singkat waktu HRT maka proses penguraiannya samakin tidak baik.
\end{abstract}

Kata kunci: Septic Tank, Desain, Air Limbah, Rumah Tangga

\section{PENDAHULUAN}

Air limbah yang dihasilkan dari kegiatan rumah tangga jika tidak dikelola dengan baik maka akan menimbulkan masalah yang serius bagi lingkungan. Salah satu solusi dalam mengatasi permasalahan air limbah, yang ada di Indonesia yaitu dengan menggunakan septic tank. septic tank merupakan salah satu alat pengelolaan limbah sederhana. Limbah yang berada di dalam septic tank dapat berpotensi mempengaruhi sumber air bersih seperti sumur, sehingga posisi sumber air bersih harus benar-benar jauh, agar terbebas dari kontaminan BOD dari septic tank (Jayanudin, et.,al, 2016). Penggunaan septic tank dapat memberikan pengaruh terhadap kualitas air, yaitu dapat menurunkan cemaran BOD pada sungai sehingga kualitas air dapat sesuai dengan standar baku mutu (Putri, et al, 2017), selain itu Septic tank juga tidak 
memakan biaya yang begitu besar dalam proses pembuatan kontruksinya.

Septic tank dapat dibuat dengan kontruksi sederhana dan dapat digunakan dengan umur teknis panjang. Septic tank pada umumnya mempunyai kontruksi yang terdiri dari 2 ruang, dan ruang pertama ukurannya sekitar $70 \%$ dan pada ruang kedua besarnya 30\% dari total ruang keseluruhan. Septic tank juga terdiri dari tangki sedimentasi yang kedap air, sebagai tempat tinja dan air buangan masuk dan mengalami dekomposisi. Di dalam tangki ini tinja akan berada selama beberapa hari (Notoatmodjo, 2003).

Septic tank umum digunakan di Indonesia karena menggunakan prinsip anaerob, yang hanya dibuat kemudian dibiarkan saja, tanpa perawatan yang rutin, dan jika ingin operasionalnya optimal maka perlu dikuras dengan jangka waktu 1 kali dalam stahun. Salah satu kelemahan dari sistem septic tank yaitu mempunya efisiensi yang rendah, karena hanya mampu menghilangkan kandungan COD sebesar $25-40 \%$ dan hasil dari effluentnya relatif rendah. Untuk kontruksinya, septic tank harus dibuat dengan ajarak kurang lebih 15 meter dari sumber air bersih. Agar proses penguraian mikroorganisme pada septic tank berjalan baik, salah satu hal yang perlu diperhatikan yaitu HRT Hydraulic retention time atau waktu saat liquid berada di dalam reaktor anaerobic (Ogejo dkk, 2009). HRT dapat mempengaruhi laju pertumbuhan dari mikroorganisme anaerobic (Hasanah, 2013). Menurut Chen dkk. (2001) dan Han dan Shin (2004) dalam Liu (2008), pemilihan HRT dapat mempengaruhi kemampuan hidrolisis bahan organik. Kemampuan ini sangat terkait dengan kapasitas penguraian senyawa kompleks organik menjadi senyawa organik sederhana yang merupakan pengendali utama keberhasilan proses pengolahan air limbah secara keseluruhan (Ahmad dkk., 2011).

\section{RUMUSAN MASALAH}

Berdasarkan hal tersebut di atas penulis bermaksud untuk membuat suatu perencanaan septic tank untuk kebutuhan domestik rumah tinggal, beserta perkiraan kualitas BOD dan COD dari Effluent seta kapasitas volume septic tank.

\section{TUJUAN PENELITIAN}

Adapun tujuan dari penelitian ini yaitu:

1. Untuk mengetaui perkiraan kualitas dari effluent (BOD \& COD) septic tank

2. Untuk mengetahui berapa kapasitas volume dari septic tank untuk rumah tempat tinggal.

\section{METODE PENELITIAN}

Metode Penelitian yang digunakan pada penelitian ini adalah metode kuantitatif

\section{Jenis Data Penelitian}

1. Data Primer

Merupakan data yang berasal dari perhitungan berdasarkan persamaan matematis, selain itu juga dengan menggunakan pembacaan Grafik dari Dewats tahun 1998

2. Data Sekunder

Data sekunder diperoleh dari studi literatur, dan dari semua sumber yang berkaitan dengan perencanaan septic tank.

\section{Teknik Analisis Data}

Data yang telah dikumpulkan kemudian dianalisis dengan metode berikut.

1. Mengasumsikan BOD dan COD effluent setelah limbah masuk ke Septic tank, yaitu dengan menghitung COD Removal rate dan Kadar COD berdasarkan Peak Flow rate $=1201 /$ hari atau $0,12 \mathrm{~m}^{3} / 15=$ $0,008 \mathrm{~m}^{3} / \mathrm{jam}$ dengan Hydraulic retention time $(\mathrm{HRT})=15$ jam (nilai Empiris)

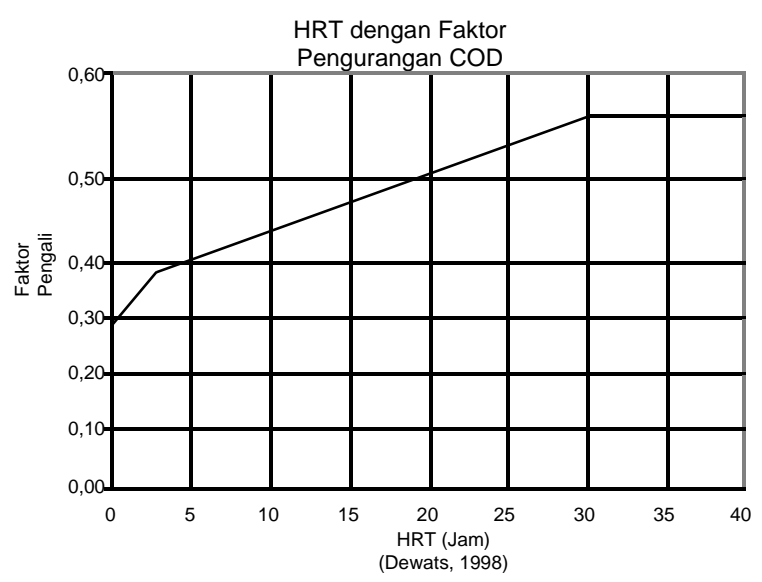

2. Pembacaan Grafik Dewats untuk Penurunan Volume Lumpur Selama 2 Tahun dengan pembacaan grafik Dewats 


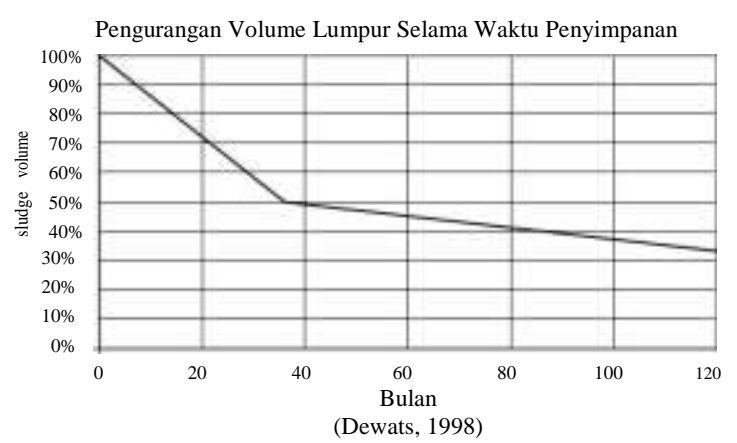

3. Kebutuhan volume septic tank untuk HRT 15 jam

\section{HASIL DAN PEMBAHASAN}

Besaran air limbah yang dihasilkan dari kegiatan rumah tangga menuju septic tank menurut Jayanudin (2016), adalah sebesar $120 \mathrm{~L} /$ hari atau $0,12 \mathrm{~m}^{3} /$ hari dengan jumlah anggota keluarga ideal yaitu 5 orang. Limbah tersebut efektif mengalir selama 12 jam. Limbah berasal dari air buangan Mandi, Cuci dan Kakus dan kegitan lainya, dan diasumsikan sebesar BOD $300 \mathrm{mg} / \mathrm{l}$ dan COD $600 \mathrm{mg} / \mathrm{l}$.

\section{Data Awal Perencanaan}

Dalam hal ini data awal untuk perencanaan yaitu:

1. HRT $=15$ jam (nilai Empiris), Hydraulic retention time adalah waktu saat liquid berada di dalam reaktor anaerobic (Ogejo dkk, 2009)

2. Peak Flow rate $=120 \mathrm{l} / \mathrm{hari}$ atau 0,12 $\mathrm{m}^{3} / 15=0,008 \mathrm{~m}^{3} / \mathrm{jam}$

3. Waktu pengurasan setiap 24 bulan

4. BOD inlet $300 \mathrm{mg} / \mathrm{l}$

5. COD inlet $600 \mathrm{mg} / \mathrm{l}$

6. Sistem septic tank anaerobic.

\section{Perkiraan Kualitas dari Effluent BOD dan COD Septic Tank}

Berdasarkan pembacaan dari grafik DEWATS (Sasse, 1998), Jika padatan dalam limbah terendapkan maka akan di dapat ratio pengendapan SS/COD antara $0,35-0,45$, dan penelitian ini mengambil nilai 0,42 atau mengalami penurunan sebesar $42 \%$ sehingga terjadi pengurangan bahan organik dari air limbah dan setiap terjadi pengurangan BOD 1 gram, maka akan menghasilkan 0,005 liter lumpur. Untuk konversi rasio penurunan COD yang diakibatkan oleh endapan ke penurunan secara total, maka rasio 0,42 akan dibagi dengan nilai empiris konversi 0,6 (Pusteklim, 2017)

\section{Penurunan Kadar COD}

Agar Proses pengolahan limbah di septic tank berjalan baik, semua tergantung pada HRT (Hydrolic Retention Time). Dalam penelitian ini nilai HRT adalah 15 jam dan faktor pengalinya 0,48 , sehingga:

1. COD Removal rate $=(0,42 / 0,6) \times 0,45=$ 0,315 atau $31,5 \%$

2. Kadar COD dari Efluent $=(1-0,315) \mathrm{x}$ $300 \mathrm{ppm}=207 \mathrm{mg} / \mathrm{ltr}$

Pengurangan COD selama pengolahan limbah pada septic tank tidak linear dengan pengurangan BOD.

\section{Penurunan Kadar COD}

Berdasarkan pembacaan grafik Dewats 1998 mengenai ratio penurunan COD dengan pengurangan $\mathrm{BOD}$, jika COD removalnya $31,5 \%$ maka diperoleh faktor konversi 1, sehingga

1. Pengurangan $\mathrm{BOD}=1 \times \mathrm{COD}$ Removal $=1 \times 31,5 \%=31,5 \%$

2. Kadar BOD effluent $=(1-0,315) \times 600$ $\mathrm{ppm}=411 \mathrm{mg} / \mathrm{l}$

\section{Volume lumpur selama 2 tahun}

Akumulasi Volume lumpur yang dihasilkan selama 2 tahun (24 Bulan) adalah:

$=0,005 \mathrm{lt} / \mathrm{gr} \times(600 \mathrm{mg} / \mathrm{lt}-411 \mathrm{mg} / \mathrm{lt}) \times 0,12$ $\mathrm{m}^{3} \times 30$ hari $\mathrm{x} 24$ bulan

$=0,005 \times 115,5 \times 13 \times 30 \times 24$

$=81,648$ liter $=0,081 \mathrm{~m}^{3}$

\section{Penurunan Volume Lumpur Selama 2 Tahun}

Lumpur yang akan diendapkan selama jangka waktu tertentu akan mengalami penyusutan dan mengalami pengurangan volume. Berdasarkan pembacaan grafik Dewats (Sasse, 1998), selama 24 bulan penurunan volume lumpur/sludge pada septic tank sebesar $68 \%$ atau Setelah 24 bulan volume lumpur menjadi $0,055 \mathrm{~m}^{3}$, semakin lama waktu penyimpanan lumpur di septic tank maka volumenya akan semakin berkurang 


\section{Kebutuhan volume septic tank untuk HRT 15 jam}

Jika Volume lumpur pada Septic tank selama 24 bulan sebesar $0,055 \mathrm{~m}^{3}$, dan HRT yang ditetapkan adalah 15 jam, maka volume septic tank yang dibutuhkan untuk menginapkan limbah selama 15 jam adalah sebesar $0,075 \mathrm{~m}^{3}$. Semakin lama waktu HRT maka akan semakin baik penguraian mikroorganisme dalam septic tank serta sebaliknya, semakin singkat waktu HRT maka proses penguraiannya samakin tidak baik.

\section{KESIMPULAN}

1. Besaran air limbah yang dihasilkan dari kegiatan rumah tangga menuju septic tank adalah sebesar $120 \mathrm{~L} / \mathrm{hari}$ atau 0,12 $\mathrm{m}^{3} /$ hari.

2. COD Removal rate sebesar $31,5 \%$ dan Kadar COD dari Efluent sebesar 207 $\mathrm{mg} / \mathrm{ltr}$

3. BOD Removal rate sebesar $31,5 \%$ dan Kadar BOD dari Efluent sebesar 411 $\mathrm{mg} / \mathrm{l}$

4. Akumulasi Volume lumpur yang dihasilkan selama 2 tahun (24 Bulan) adalah sebesar 81,648 liter $=0,081 \mathrm{~m}^{3}$

5. penurunan volume lumpur/sludge pada septic tank sebesar $68 \%$ atau Setelah 24 bulan volume lumpur menjadi $0,055 \mathrm{~m}^{3}$. semakin lama waktu penyimpanan lumpur di septic tank maka volumenya akan semakin berkurang

6. Volume septic tank yang dibutuhkan untuk menginapkan limbah selama 15 jam adalah sebesar $0,075 \mathrm{~m}^{3}$. Semakin lama waktu HRT maka akan semakin baik penguraian mikroorganisme dalam septic tank serta sebaliknya, semakin singkat waktu HRT maka proses penguraiannya samakin tidak baik.

\section{DAFTAR PUSTAKA}

Ahmad, A., Yelmida, dan Arjunita, 2011, Penyisihan Karbohidrat dari Limbah Cair PKS dengan Bioreaktor Hibrid Anaerob Bermedia Cangkang Sawit. Prosiding Nasional Teknik Kimia Kejuangan, 212-216.
Jayanudin., Fahrurrozi, M., 2016, Pemodelan Resiko Kontaminasi Sumur Rakyat oleh Sumur Resapan Limbah Septic Tank, Jurnal Teknika, 12 (1), 01-15.

Liu, D., 2008, Bio-hydrogen Production by Dark Fermentationfrom Organic Wastes and Residues, Disertation, Department of Environmental Engineering, Technical University of Denmark. 2.

Notoatmodjo, S., 2003, Ilmu Kesehatan Masyarakat (Prinsip-prinsip Dasar), Jakarta, PT. Rineka Cipta.

Ogejo, J.A., Whn, Z., Ignosh, J., Bendfeldt, E., dan Collins, E. R., 2009, Biomethane Technology. Virginia Cooperative Extention Publication, Communications and Marketing, College of Agriculture and Life Sciences, Virginia Polytechnic Institute and State University. 1-5.

Putri, J.R., Sutrisno, E., Wardana, I.W., 2017, Pengaruh Pengelolaan Limbah Domestik Dengan Peningkatan Jumlah Septic Tank Terhadap Beban Cemaran Bod Di Kali Semarang Menggunakan Program Qual2e, Jurnal Teknik Lingkungan.

Pusteklim, 2017, Manual Teknologi Tepat Guna, Instalasi pengolahan Air Limbah.

Rekoyoso, B., Syafrudin., S., 2014, Pengaruh Hydraulic Retention Time (Hrt) Dan Konsentrasi Influen Terhadap Penyisihan Parameter Bod Dan Cod Pada Pengolahan Limbah Domestik Greywater Artificial Menggunakan Reaktor Uasb, Jurnal Teknik Lingkungan, 03 (1).

Sasse, L. 1998. Decentralised Wastewater Treatment in Developing Countries (DEWATS). 